\title{
Degradação térmica de fluidos de perfuração argilosos aditivados com polímeros e lubrificante
}

\author{
Thermal degradation of clay drilling fluids \\ with polymers and lubricant additives
}

\author{
Renalle Cristina Alves de Medeiros Nascimento ${ }^{1}$, Juliano Magalhães ${ }^{3}$, \\ Eugênio Pereira ${ }^{3}$, Luciana Viana Amorim²
}

\author{
${ }^{1}$ Programa de Pós-Graduação em Ciências e Engenharia de Materiais, UAEMa/CCT/UFCG, \\ Rua Aprígio Veloso, 882, cep 58429-140, Campina Grande, PB. \\ e-mail: nalenascimento@gmail.com \\ ${ }^{2}$ SystemMud Ind. e Com. Ltda., Dep. Química, \\ Rua Álvaro Beraldi, 421, cep 88307-740, Carvalho, SC. \\ e-mail: juliano@systemmud.com.br ; eugenio.pereira@imdexlimited.com \\ ${ }^{3}$ Unidade Acadêmica de Engenharia Mecânica, UEM/CCT/UFCG, \\ Rua Aprígio Veloso, 882, cep 58429-140, Campina Grande, PB. \\ e-mail: luciana@dem.ufcg.edu.br
}

\section{RESUMO}

O comportamento de fluidos de perfuração em altas temperaturas, particularmente aqueles à base de água, é imprevisível e, de fato, ainda não foi totalmente compreendido. Desta forma, otimizar a composição dos fluidos surge como um dos principais fatores para controle das suas propriedades, uma vez que as propriedades reológicas dos fluidos podem apresentar grandes diferenças à temperatura ambiente e no interior do poço. Este trabalho teve como objetivo avaliar o comportamento de fluidos argilosos aditivados com polímeros e lubrificante em elevada temperatura. Para tanto, foram feitos estudos das propriedades reológicas, de filtração e pH. Os resultados evidenciaram que os fluidos estudados apresentaram baixos valores de propriedades reológicas e altos valores de propriedades de filtração. Mostraram também que o envelhecimento térmico ocasionou um processo de degradação dos aditivos utilizados, resultando na redução do pH e na caramelização dos fluidos.

Palavras-chave: Fluidos de perfuração. temperatura. degradação. aditivos.

\section{ABSTRACT}

The behavior of drilling fluids at high temperatures, particularly those which are water based drilling fluids, is unpredictable and, , has not been totally understood. In this way, optimizing the composition of the fluids becomes one of the main factors for the control of their properties. This is so because the rheological properties of the drilling fluids can present great differences at ambient temperature and in the interior of the well. This work aimed to evaluate the behavior of clay drilling fluids with polymer and lubricant additives at high temperature. Therefore studies were performed on the rheological properties, filtration and $\mathrm{pH}$. The results evidenced that the fluids studied presented low values for the rheological properties and high values for the filtration properties. In addition to that, thermal aging caused a degradation process of the additives used, mainly the xanthan gum, resulting in $\mathrm{pH}$ reduction and in the caramelization of the fluids.

Keywords: Drilling fluids, Temperature, Degradation, Additives.

\section{INTRODUÇÃO}

Os fluidos de perfuração são indispensáveis à indústria do petróleo. Constituem o elemento mais importante na operação de perfuração e tiveram suas tecnologias desenvolvidas e ampliadas à proporção que as perfurações atingiam grandes profundidades e surgiam necessidades de controles paramétricos cada vez mais 
rígidos [1].

A formulação ideal de um fluido é importante uma vez que diversos problemas podem ser causados caso o fluido de perfuração não esteja de acordo com o sistema a ser perfurado. Esses problemas, segundo GUIMARÃES e ROSSI [2], podem ser: perda de circulação, ineficiência da limpeza do poço, potencial formação de hidratos, dentre outros. Além disto, custo, resistência à contaminação, disponibilidade de água, pressão da formação e inclinação do poço são também significativos na escolha do fluido a ser adotado [3].

Outro fator importante na formulação de fluidos é a crescente preocupação quanto ao desenvolvimento de novas tecnologias que garantam a preservação do meio ambiente. Por isto, tem-se procurado desenvolver fluidos com produtos de outras fontes diferentes do petróleo, suscetíveis à biodegradação, com redução do impacto ambiental causado pelo descarte dos cascalhos, sem bioacumulação e, finalmente, com baixa toxicidade. Neste sentido, o uso de fluidos à base de água mostra-se interessante, visto que, além da possibilidade do uso de matéria-prima sem modificação química, a não utilização de óleo na sua fase contínua contribui potencialmente para sua não toxicidade [4].

A principal função da água nesse tipo de fluido é prover o meio de dispersão para os materiais coloidais, principalmente argilas e polímeros [5]. Dentre os vários fluidos utilizados, destacam-se os argilosos, constituídos essencialmente por água e argila. Esses fluidos geralmente são utilizados nas primeiras fases de perfuração, sendo empregada a argila bentonita sódica em sua preparação devido à sua elevada capacidade de hidratação. Esta argila é adicionada para desempenhar uma ou mais das seguintes funções: aumentar a capacidade de limpeza do poço pelo aumento da viscosidade do fluido; reduzir as infiltrações nas formações permeáveis pela formação de uma membrana de baixa permeabilidade (reboco); e manter os detritos em suspensão durante as conexões e manobras. Essa última função é alcançada pela capacidade da argila de formar géis tixotrópicos [6].

A composição do fluido depende das exigências particulares de cada perfuração. Segundo LUMMUS e AZAR [3], em perfurações simples e pouco profundas, um fluido constituído de água e argila bentonítica é adequado, e em situações de difícil perfuração e/ou grandes profundidades, é necessário um fluido mais elaborado, com introdução de vários aditivos.

Os polímeros mais utilizados na formulação de fluidos aquosos eram a carboximetilcelulose (CMC), celulose polianiônica (PAC) e poliacrilamida parcialmente hidrolisada (PHPA). Entretanto, esses polímeros são muito sensíveis às condições de alta salinidade, que diminuem sua eficiência [7]. Com isso, a goma xantana passou a ser amplamente utilizada para este propósito, pois suas soluções são altamente estáveis em ampla faixa de $\mathrm{pH}$, sendo afetadas apenas por valores de $\mathrm{pH}$ superiores a 11 e inferiores a 2,5. Essa estabilidade depende da concentração: quanto maior a concentração, maior a estabilidade da solução. Além disso, a goma xantana é estável em ampla faixa de temperatura e sua viscosidade é pouco afetada na presença de sais [8].

A goma xantana é um polissacarídeo sintetizado por uma bactéria fitopatogênica do gênero Xanthomonas e tem extrema importância comercial. Foi aprovada pelo FDA (Food and Drug Administration) em 1969, sendo aplicada a inúmeros produtos em diferentes segmentos industriais, como alimentos, fármacos, cosméticos, químicos e petroquímicos. Essa ampla aplicação deve-se, principalmente, às suas propriedades reológicas, que permitem a formação de soluções viscosas a baixas concentrações $(0,05$ $1,0 \%)[9]$.

Os polímeros devem apresentar alta viscosidade em baixas concentrações, comportamento pseudoplástico e viscosidade estável em meio a variações de salinidade, temperatura e condições alcalinas [10]. Soluções de goma xantana são altamente pseudoplásticas, ou seja, a viscosidade diminui com o aumento da taxa de deformação. No entanto, recuperam rapidamente a viscosidade na remoção da tensão de cisalhamento; logo, o fenômeno da histerese não é pronunciado [11]. A associação das cadeias de goma xantana existe quando em repouso ou em baixas taxas de cisalhamento, sendo estabilizadas pelas ligações de hidrogênio [12]. No cisalhamento, a extensão da agregação é reduzida pelo alinhamento das cadeias, resultando em uma baixa viscosidade [7].

A CMC é um polímero aniônico compatível com sais monovalentes. Assim como a goma xantana, é estável para uma ampla faixa de temperatura e funciona como controlador de filtrado e modificador reológico. Devido à rigidez de sua molécula, a CMC possui boa resistência ao cisalhamento hidráulico dos jatos da broca de perfuração [13].

A carboximetilcelulose, normalmente apresentada na forma sódica (sal de sódio), como carboximetilcelulose de sódio, é um polímero aniônico derivado da celulose, de baixo custo, que possui cadeia linear e é solúvel em água [13]. O uso da CMC de baixa massa molar reduz as perdas por filtração e produz rebocos muito finos e capazes de impedir o escoamento do fluido através das formações geológicas 
que estão sendo perfuradas [14].

Além de aditivos poliméricos, lubrificantes são bastante utilizados para compensar a deficiência de lubrificação apresentada pelos fluidos à base de água. Esses aditivos consistem em compostos de superfícies ativas que possuem afinidade por superfícies metálicas, as quais estão em constante contato com as formações geológicas ou mesmo com outras superfícies metálicas [15]. Muitos estudos têm mostrado que a adição de determinados lubrificantes reduz o risco de problemas como prisão diferencial, além de reduzir a força necessária para liberar a tubulação ou ferramenta [16].

Segundo REID et al. [17], os lubrificantes mais eficazes são aqueles que operam por vários mecanismos, dependendo da sua composição química e do estado de dispersão no fluido. Estes podem revestir superfícies metálicas, reduzindo a aderência do aço ao reboco; podem ser incorporados ao reboco e proporcionar um melhor controle da perda de fluido (resultando em rebocos finos); e podem ser incorporados ao reboco de uma forma que reduza a elasticidade do mesmo.

Além da dificuldade de lubrificação, os fluidos à base de água, especialmente os fluidos argilosos, são sensíveis a altas temperaturas e, quando expostos por longos períodos, formam géis rígidos, podendo comprometer as operações de perfuração [18].

De acordo com KELLY [19], as propriedades reológicas dos fluidos de perfuração podem apresentar grandes diferenças à temperatura ambiente e no interior do poço. A temperatura no interior do poço depende do gradiente geotérmico e pode ser superior a $260{ }^{\circ} \mathrm{C}$. Mesmo as temperaturas moderadas podem ter influência siginiticativa nas propriedades reológicas dos fluidos. $\mathrm{O}$ fluido no interior do poço pode ser mais ou menos viscoso do que na superfície, e um aditivo que reduz a viscosidade na superfície pode aumentá-la no interior dos poços.

Devido ao grande número de variáveis envolvidas, é imprevisível e, de fato, ainda não totalmente compreendido o comportamento de fluidos de perfuração em altas temperaturas, em particular aqueles à base de água,. Mesmo diferenças muito pequenas na composição destes fluidos podem alterar consideravelmente seu comportamento reológico, de modo que é necessário testar cada fluido individualmente, a fim de obter dados confiáveis [20].

Diante do exposto, este trabalho teve como objetivo avaliar a estabilidade térmica de fluidos de perfuração argilosos, aditivados com polímeros e lubrificante, sob elevada temperatura.

\section{MATERIAIS E MÉTODOS}

\subsection{Materiais}

Para preparação dos fluidos de perfuração de base aquosa, foram utilizados os seguintes aditivos: argila bentonítica ativada, goma xantana, carboximetilcelulose de baixa viscosidade (CMC BV) e lubrificante. A Tabela 1 apresenta a composição do fluido estudado.

Para essa mesma composição, foi utilizada a temperatura ambiente e as temperaturas de $107^{\circ} \mathrm{C}, 121{ }^{\circ} \mathrm{C}$ e 177 ${ }^{\circ} \mathrm{C}$ para envelhecer os fluidos denominados, respectivamente, de $\mathrm{FT}_{\mathrm{amb}}, \mathrm{FT}_{1}, \mathrm{FT}_{2}$ e $\mathrm{FT}_{3}$.

Tabela 1: Composição do fluido de perfuração estudado.

\begin{tabular}{l|l}
\hline ADITIVOS & FLUIDO \\
\hline Água $(\mathrm{mL})$ & 350,0 \\
\hline Argila $(\mathrm{g})$ & 8,75 \\
\hline Goma xantana $(\mathrm{g})$ & 0,7 \\
\hline CMC BV $(\mathrm{g})$ & 1,0 \\
\hline Lubrificante $(\mathrm{mL})$ & 3,5 \\
\hline
\end{tabular}

\subsection{Métodos}




\subsubsection{Caracterização dos aditivos poliméricos}

A caracterização dos polímeros foi realizada por meio de ensaios de Calorimetria Exploratória Diferencial (DSC), com o auxílio do equipamento Shimadzu DSC-50 em atmosfera de ar, com o objetivo de se determinar as temperaturas de decomposição dos aditivos. Foram utilizados aproximadamente 3,0 mg de amostra em uma faixa de temperatura de $25{ }^{\circ} \mathrm{C}$ a $350{ }^{\circ} \mathrm{C}$, com taxa de aquecimento de $10{ }^{\circ} \mathrm{C} / \mathrm{min}$. A temperatura de decomposição do lubrificante foi fornecida pelo fabricante.

\subsubsection{Preparação dos fluidos de perfuração}

Para preparação dos fluidos, a argila foi adicionada à água sob agitação constante por 20min, a uma velocidade de $13.000 \mathrm{rpm}$, em agitador Hamilton Beach, modelo 936. Os aditivos foram adicionados a cada 5 min de agitação. Assim, após a adição da argila e passados $5 \mathrm{~min}$, foi acrescentada aos fluidos a goma xantana, depois a CMC BV e, por fim, o lubrificante. Os fluidos avaliados à temperatura ambiente permaneceram em repouso por $24 \mathrm{~h}$, em recipiente fechado.

\subsubsection{Envelhecimento dos fluidos de perfuração}

Ao término da preparação dos fluidos, os mesmos foram submetidos ao envelhecimento térmico em forno Roller Over, modelo $705 \mathrm{ES}$, da marca Fann, nas temperaturas de $107{ }^{\circ} \mathrm{C}, 121{ }^{\circ} \mathrm{C}$ e $177{ }^{\circ} \mathrm{C}$. O envelhecimento foi realizado sob condição dinâmica durante o período de 16h, conforme normas API [21].

\subsubsection{Propriedades reológicas}

Foram determinados, em viscosímetro Fann 35A, de acordo com as normas API [21], a viscosidade aparente (VA), a viscosidade plástica (VP) e o limite de escoamento (LE).

A viscosidade aparente (VA) é o valor obtido na leitura a $600 \mathrm{rpm}$ dividido por 2 , dada em $\mathrm{cP}$. A viscosidade plástica (VP) é a diferença das leituras realizadas a $600 \mathrm{rpm}$ e a $300 \mathrm{rpm}$, dada também em cP. O limite de escoamento é a diferença entre a viscosidade plástica e a leitura em $300 \mathrm{rpm}$, dada por N/m². Os ensaios foram realizados à temperatura ambiente e em duplicata.

\subsubsection{Propriedades de filtração}

Foram utilizados filtros-prensa API para determinação do volume de filtrado. Os fluidos foram submetidos a uma pressão de 100 psi por 30min à temperatura ambiente, segundo a norma API [21]. Em seguida, foi coletado o volume de filtrado. Os ensaios foram realizados em duplicata.

Para determinar a espessura de reboco, foi adotada uma metodologia desenvolvida por FARIAS [22] com base na norma API 13B-1 [23]. Com o auxílio de extensômetro, foram feitas 5 leituras de espessura de reboco em diferentes pontos do mesmo. Após a obtenção das medidas, foi feita uma média aritmética das cinco determinações.

\subsection{6 pH}

$\mathrm{O}$ pH foi determinado em pHmetro digital da marca Gehaka, modelo PG 1000.

Todos os ensaios foram realizados em duplicata.

\section{RESULTADOS E DISCUSSÃO}

As curvas de DSC estão apresentadas nas Figuras 1 (a) e (b). A partir das curvas de DSC dos polímeros utilizados no preparo dos fluidos de perfuração, foi possível observar que a goma xantana e a carboximetilcelulose (CMC) apresentaram comportamentos semelhantes quando submetidos às mesmas condições de temperatura. Na Figura 1 (a), observaram-se dois eventos: um pico endotérmico e outro exotérmico. O primeiro evento variou entre $25{ }^{\circ} \mathrm{C}$ e $150{ }^{\circ} \mathrm{C}$ e apresentou um pico endotérmico a $86{ }^{\circ} \mathrm{C}$, referente à perda de água adsorvida, devido à umidade do polímero. $\mathrm{O}$ segundo evento, com pico exotérmico, teve início a $250{ }^{\circ} \mathrm{C}$ e refere-se à degradação do material.

VILLETTI et al. [24] realizaram estudos de DSC a temperaturas acima de $300{ }^{\circ} \mathrm{C}$ e observaram ainda um pico entre $400{ }^{\circ} \mathrm{C}$ e $550{ }^{\circ} \mathrm{C}$, referente à carbonização da goma xantana. Já a $750{ }^{\circ} \mathrm{C}$, foi observada a presença de resíduo, ou seja, material inorgânico. $\mathrm{O}$ valor de resíduo observado na goma xantana é devido à presença de íons $\mathrm{Na}^{+}$em sua estrutura - tais íons podem formar diferentes compostos inorgânicos durante o processo de degradação [25]. 
Na Figura 1 (b), também foram observados dois eventos: o primeiro endotérmico e o segundo exotérmico. O primeiro evento teve pico em $92^{\circ} \mathrm{C}$. O início do pico em aproximadamente $27{ }^{\circ} \mathrm{C}$ pode estar associado à evaporação de água residual absorvida na amostra; e o fim do pico em $125^{\circ} \mathrm{C}$ corresponde ao início das modificações na cadeia polimérica (diferença entre as fases cristalina e amorfa). O segundo evento com pico exotérmico, que teve início em aproximadamente $250{ }^{\circ} \mathrm{C}$, correspondente à degradação do material, relacionada com as modificações das cadeias poliméricas devido às reações de despolimerização e decomposição térmica, resultando na formação de produtos voláteis de baixa massa molecular $\left(\mathrm{H}_{2} \mathrm{O}, \mathrm{CO}\right.$, $\mathrm{CO}_{2}, \mathrm{NH}_{3}$ e $\mathrm{CH}_{4}$ ). Segundo reportado por FRANCO [26], outro evento ainda pode ser observado e está relacionado à degradação oxidativa devido à carbonização do material analisado.

Quanto ao lubrificante estudado, segundo dados fornecidos pelo fabricante, o mesmo apresenta uma temperatura de degradação superior a $200{ }^{\circ} \mathrm{C}$. O lubrificante estudado é um éster de ácidos graxos de cadeia curta e etanol, insolúvel e imiscível em água, não possui cargas, forma gotículas no fluido e, ao entrar em contato com superfícies metálicas, adere a estas superfícies apresentando um grande poder de lubrificação [27].

Os resultados obtidos por meio dos ensaios de DSC dos aditivos estudados (goma xantana e CMC) e os dados referentes ao lubrificante evidenciaram que a temperatura de degradação dos mesmos é superior a $200{ }^{\circ} \mathrm{C}$.

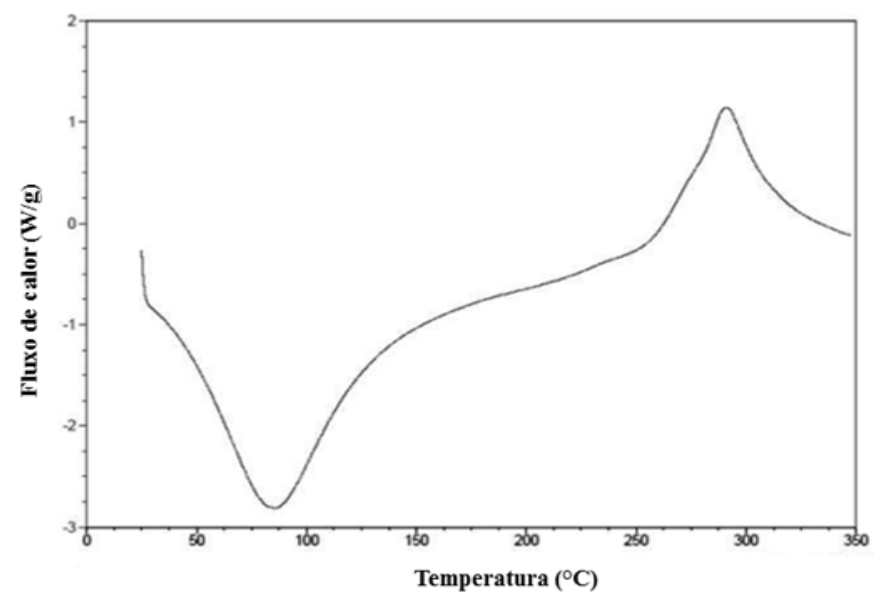

(a)

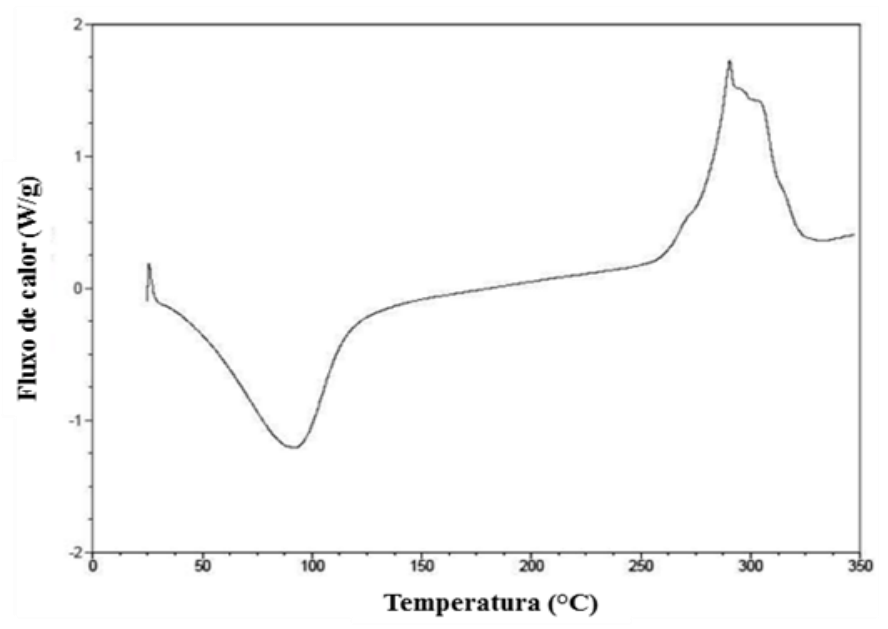

(b)

Figura 1: Curvas de DSC dos aditivos (a) goma xantana e (b) CMC.

A Figura 2 apresenta os resultados das propriedades reológicas dos fluidos à temperatura ambiente 
$\left(\mathrm{FT}_{\mathrm{amb}}\right)$ e envelhecidos às temperaturas de $107{ }^{\circ} \mathrm{C}\left(\mathrm{FT}_{1}\right), 121^{\circ} \mathrm{C}\left(\mathrm{FT}_{2}\right)$ e $177{ }^{\circ} \mathrm{C}\left(\mathrm{FT}_{3}\right)$.

Pode-se observar que o aumento da temperatura de envelhecimento promoveu uma redução das viscosidades aparente e plástica e do limite de escoamento dos fluidos estudados. À temperatura ambiente, os fluidos apresentaram valores de VA de 30,0 cP, VP de 14,0 cP e LE de $32,0 \mathrm{~N} / \mathrm{m}^{2}$.

Comparando os resultados dos fluidos submetidos somente à temperatura ambiente $\left(\mathrm{FT}_{\mathrm{amb}}\right)$ com os envelhecidos a $107{ }^{\circ} \mathrm{C}\left(\mathrm{FT}_{1}\right)$, observou-se redução brusca nas propriedades reológicas dos fluidos após envelhecimento. Para os demais fluidos $\left(\mathrm{FT}_{2}\right.$ e $\left.\mathrm{FT}_{3}\right)$, com o aumento da temperatura de envelhecimento houve uma redução destas propriedades. No entanto, essa redução não foi tão pronunciada como a observada entre os fluidos $\mathrm{FT}_{\mathrm{amb}}$ e $\mathrm{FT}_{1}$.

Segundo MORIYAMA e NETO [28], os fluidos de perfuração à base de água têm suas propriedades reológicas modificadas quando submetidos a altas temperaturas, de forma que suas grandezas medidas na superfície são sempre diferentes daquelas no fundo do poço, o que pode ser considerado como uma diminuição de sua eficiência, já que os fluidos são dimensionados a fim de se obter graus específicos para cada uma de suas propriedades, e qualquer alteração nestas provocará uma alteração no cenário de trabalho.

Em meio aquoso, a transferência de quantidade de movimento devido à atividade molecular é pequena em comparação à força de coesão entre as moléculas. Por isso, a tensão de cisalhamento $(\tau)$ e a viscosidade ( $\mu$ ) dependem principalmente da ordem de grandeza destas forças de coesão, que tendem a manter as moléculas adjacentes em uma posição fixa, resistindo, portanto, ao movimento [29]. Com o aumento da temperatura, tem-se o aumento do movimento Browniano e a redução das forças de coesão com consequente redução das interações eletrostáticas. Como resultado, tem-se a redução da viscosidade.

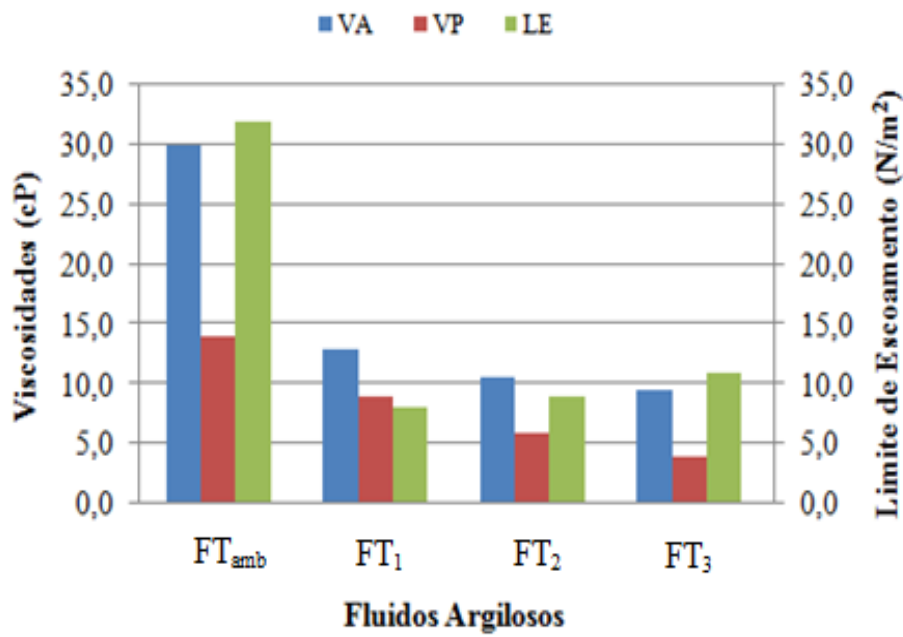

Figura 2: Propriedades reológicas dos fluidos de perfuração argilosos: VA= viscosidade aparente; VP = viscosidade plástica; e LE = limite de escoamento.

Segundo MATOS [30], o aumento da temperatura promove uma redução da viscosidade do lubrificante, presente nos fluidos de perfuração, porque a viscosidade é inversamente proporcional à temperatura. Desta forma, os valores de viscosidades dos fluidos aditivados com lubrificante devem apresentar redução a altas temperaturas. Diante desta afirmação, os menores valores de viscosidades e de limite de escoamento observados neste estudo (Figura 2) podem ser atribuídos também a este fato.

Além disso, o lubrificante estudado, por ser insolúvel em água e não possuir cargas, apenas dipolos, forma, na presença de água, micelas que dificultam as interações químicas entre as partículas de argila, por impedimento espacial. Como resultado, tem-se o efeito de dispersão com redução nas propriedades reológicas e de filtração dos fluidos. Por formar micelas, as moléculas do lubrificante são anfifílicas e consistem de uma parte hidrofílica polar (iônica ou não iônica), conhecida como "cabeça polar", ligada a uma cadeia hidrocarbônica hidrofóbica, denominada "cauda apolar". Essas características em uma única molécula conduzem a um fenômeno de autoconstrução das moléculas em soluções diluídas, de maneira a proteger a parte apolar e, ao mesmo tempo, expor a parte polar à água [31].

A Figura 3 apresenta os resultados das propriedades de filtração dos fluidos argilosos estudados à temperatura ambiente $\left(\mathrm{FT}_{\mathrm{amb}}\right)$ e envelhecidos às temperaturas de $107^{\circ} \mathrm{C}\left(\mathrm{FT}_{1}\right), 121^{\circ} \mathrm{C}\left(\mathrm{FT}_{2}\right)$ e $177^{\circ} \mathrm{C}\left(\mathrm{FT}_{3}\right)$. 


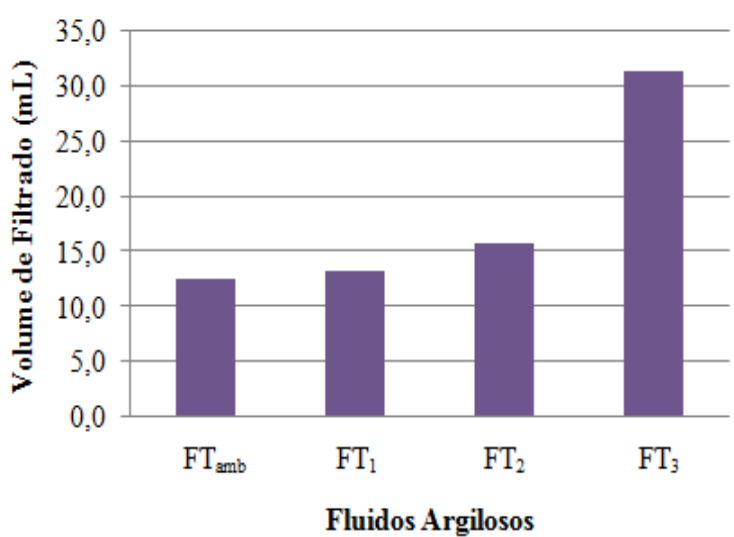

(a)

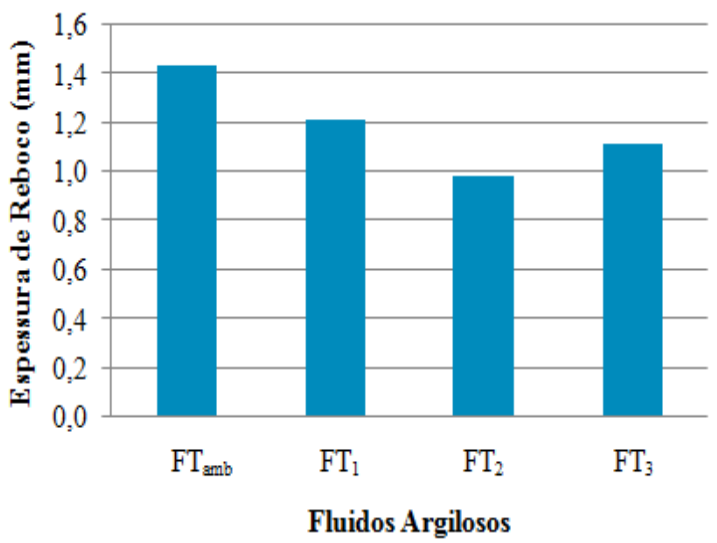

(b)

Figura 3: Propriedades de filtração dos fluidos de perfuração argilosos: (a) volume de filtrado e (b) espessura de reboco.

À temperatura ambiente, os fluidos argilosos aditivados com polímeros e lubrificante tendem a apresentar melhor comportamento reológico e menor perda por filtração. Isto acontece porque, no meio aquoso, o polímero se expande, devido à hidratação das cadeias poliméricas, diminuindo a água livre presente no sistema - como consequência, tem-se o aumento da viscosidade e a redução no VF. Esse fenômeno torna-se mais pronunciado quando há presença de argila bentonítica no fluido. O polímero interage com a argila devido à formação da camada de adsorção entre as cargas negativas do polímero e as cargas positivas presentes nas arestas das partículas de argila.

O efeito da temperatura também foi observado nas propriedades de filtração dos fluidos, pois os mesmos apresentaram maiores valores de VF com o aumento da temperatura de envelhecimento. Quanto à espessura de reboco, foi observado o comportamento inverso, ou seja, redução da espessura de reboco com o aumento da temperatura.

Segundo LOMBA [32], modificações na temperatura podem afetar o filtrado através de mudanças no equilíbrio eletroquímico que governa o grau de floculação e agregação das partículas de argila, alterando a permeabilidade do reboco. Além disso, a degradação térmica dos componentes do fluido é outro mecanismo que pode afetar o filtrado. Como muitos produtos são de natureza orgânica, no meio aquoso, ou seja, quando estão hidratados, começam a se decompor a temperaturas acima de $100{ }^{\circ} \mathrm{C}$ e essa taxa de degradação cresce com o aumento da temperatura. Provavelmente, isso se deve às mudanças na interação entre polímeropolímero, polímero-lubrificante, lubrificante-argila e polímero-argila, e de como estão conformados no fluido.

Assim, a temperatura imposta ao sistema promoveu um rearranjo das estruturas moleculares resultante da minimização da energia de solvatação, aproximando as moléculas umas das outras, reduzindo o seu volume hidrodinâmico, aumentando a quantidade de água livre no sistema e, desta maneira, aumentando o VF.

Além destes fatores, a temperatura elevada favorece a hidrólise. A hidrólise em polissacarídeos (ramificação da goma xantana), por exemplo, pode promover a quebra da ligação glicosídica (C-O), com ruptura da cadeia principal do polímero e redução da sua massa molar. Essa quebra promove a redução do tamanho da cadeia polimérica e do volume hidrodinâmico, com consequente redução da viscosidade e aumento de VF. No caso do éster, a hidrólise levará à formação do ácido carboxílico correlato, principalmente na presença de argila, que pode favorecer esse processo.

Os fluidos $\mathrm{FT}_{\text {amb }}$, sem envelhecimento, apresentaram os menores valores de $\mathrm{VF}$ e o maior valor de ER: $12,6 \mathrm{~mL}$ e $1,430 \mathrm{~mm}$, respectivamente.

Os maiores volumes de filtrado foram obtidos para os fluidos $\mathrm{FT}_{2}$ e $\mathrm{FT}_{3}$. A Figura 4 apresenta a foto do filtrado e do reboco obtido após os ensaios de volume de filtrado dos fluidos $\mathrm{FT}_{3}$. 


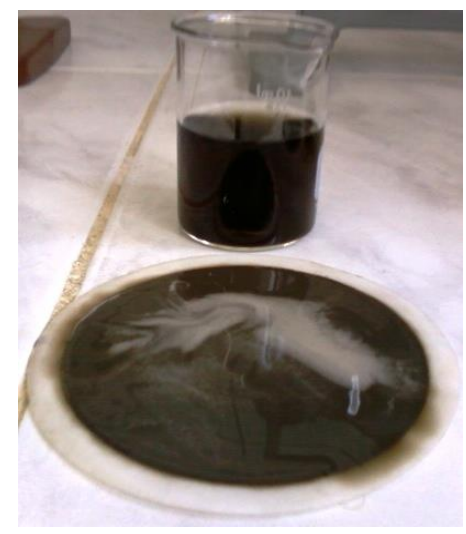

Figura 4: Aspecto do volume de filtrado e reboco do fluido argiloso envelhecido a $177^{\circ} \mathrm{C}$.

A Figura 5 mostra fotos dos fluidos argilosos à temperatura ambiente e após envelhecimento a $107{ }^{\circ} \mathrm{C}$, $121{ }^{\circ} \mathrm{C}$ e $177{ }^{\circ} \mathrm{C}$ por 16 horas.

Antes do envelhecimento, o fluido apresenta uma coloração próxima à da argila bentonítica, ou seja, bege. Após o envelhecimento, esta coloração muda completamente, passando para marrom muito escuro, próximo ao preto. Sugere-se que a coloração observada nos fluidos envelhecidos termicamente deve-se ao processo de caramelização. De acordo com FENNEMA [33], o aquecimento de carboidratos, em especial de sacarose e de açúcares redutores, em ausência de compostos nitrogenados, produz uma série de reações muito complexas, que são conhecidas como caramelização.

O processo de caramelização observado nos fluidos de perfuração deve-se à presença da goma xantana e do lubrificante, uma vez que a sacarose (principal fator para caramelização) e o álcool etílico são insumos básicos para a produção da goma xantana, como substrato da fermentação e para a separação da goma, respectivamente [7]. O lubrificante também pode ter contribuído com esse processo, uma vez que é proveniente do etanol e, na reação de hidrólise, gera um ácido carboxílico e um álcool - nesse caso, o etanol.

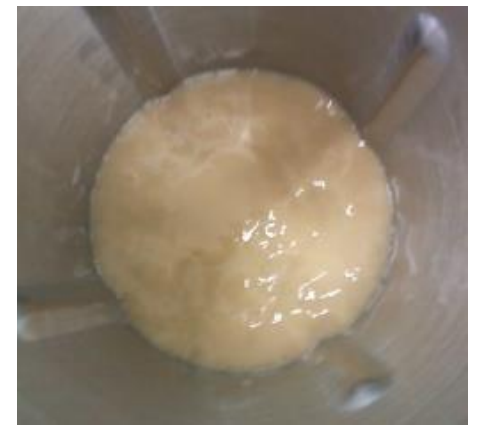

(a)

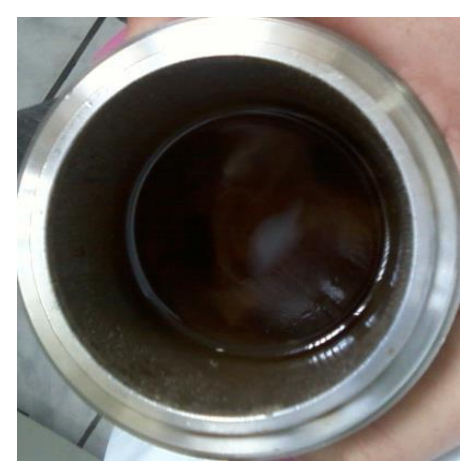

(c)

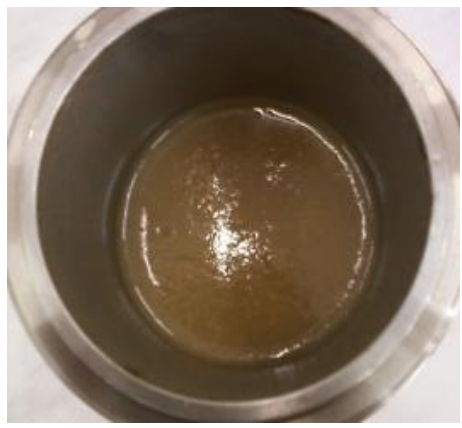

(b)

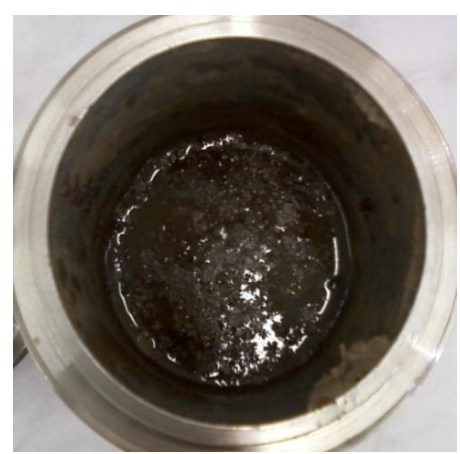

$(\mathrm{d})$

Figura 5: Aspecto dos fluidos estudados à (a) temperatura ambiente $\left(\mathrm{FT}_{\mathrm{amb}}\right)$ e envelhecidos a (b) $107{ }^{\circ} \mathrm{C}\left(\mathrm{FT}_{1}\right),(\mathrm{c}) 121$ ${ }^{\circ} \mathrm{C}\left(\mathrm{FT}_{2}\right)$ e (d) $177{ }^{\circ} \mathrm{C}\left(\mathrm{FT}_{3}\right)$. 
De acordo com COULTATE [34], quando os açúcares são aquecidos a temperaturas acima de $100{ }^{\circ} \mathrm{C}$, uma série completa de reações se processa, dando origem a uma ampla variedade de compostos aromatizantes, bem como a pigmentos escuros associados à caramelização. Os açúcares no estado sólido são relativamente estáveis ao aquecimento moderado, mas, conforme mencionado por ARAÚJO [35], quando submetidos a temperaturas acima de $120^{\circ} \mathrm{C}$, são pirolisados para diversos produtos de degradação, escuros e de alto peso molecular, denominados caramelos. Essa reação envolve a degradação do açúcar na ausência de aminoácidos ou proteínas.

A Figura 6 apresenta os resultados de $\mathrm{pH}$ dos fluidos argilosos.

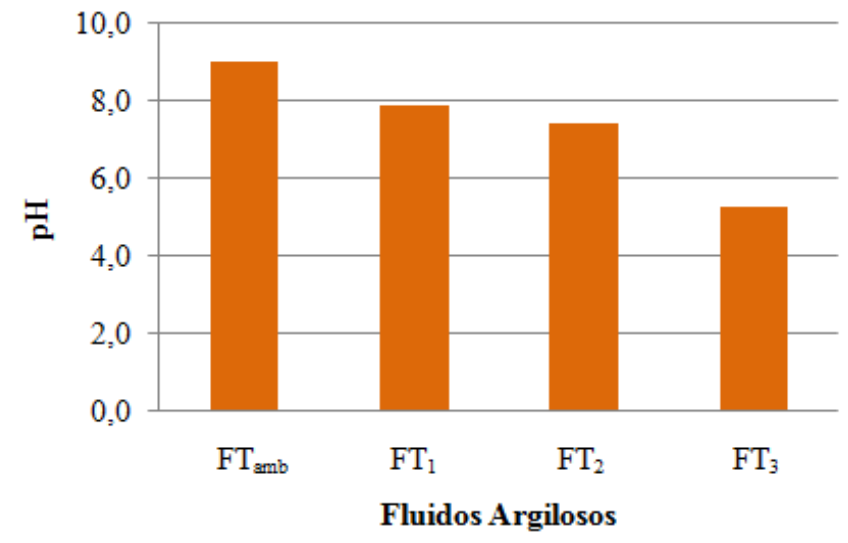

Figura 6: pH dos fluidos de perfuração argilosos.

Observou-se na Figura 6 que o pH dos fluidos argilosos à temperatura ambiente $\left(\mathrm{FT}_{\mathrm{amb}}\right)$ apresentou caráter básico, com valor de 9,0, desejável para os fluidos de perfuração. O aumento da temperatura de envelhecimento resultou na redução do $\mathrm{pH}$. Os fluidos $\mathrm{FT}_{1}$ apresentaram $\mathrm{pH}$ próximo a 8,0; os fluidos $\mathrm{FT}_{2}$, valores próximos a 7,5; e os $\mathrm{FT}_{3}$ com menores valores de $\mathrm{pH}$ e caráter ácido, próximos a 5,0. Provavelmente, o processo degradativo dos aditivos presentes nos fluidos estudados contribuiu para a redução e para os baixos valores de $\mathrm{pH}$. Ressalta-se que os fluidos de perfuração aquosos normalmente apresentam pH básico.

Segundo ARAÚJO et al. [36], além do aumento da temperatura, o pH também favorece o processo de caramelização. De acordo com os dados de $\mathrm{pH}$ apresentados na Figura 6 e as imagens mostradas na Figura 5, os fluidos envelhecidos à temperatura de $177{ }^{\circ} \mathrm{C}$ foram os que apresentaram valores de $\mathrm{pH}$ ácido, corroborando a teoria dos autores acima mencionados [36].

Segundo os resultados de DSC, a degradação dos aditivos isolados e em pó tem início a temperaturas superiores a $200{ }^{\circ} \mathrm{C}$. Contudo, foi observado que os fluidos argilosos aditivados com goma xantana, CMC e lubrificante (aditivos hidratados e misturados) se degradaram a temperaturas inferiores a essa. Essa degradação é mais pronunciada nos fluidos envelhecidos a $177^{\circ} \mathrm{C}$, embora sinais de degradação tenham sido observados a temperaturas inferiores.

Os distintos comportamentos, referentes à degradação térmica dos aditivos isolados e dos fluidos, podem ser justificados com base em dois fatores. O primeiro é que, quando dos ensaios de DSC para o conhecimento da estabilidade térmica dos aditivos, os mesmos, na forma não hidratada, permanecem na temperatura de degradação durante um curto intervalo de tempo, visto que a taxa de aquecimento é de 10 ${ }^{\circ} \mathrm{C} /$ min. Além disso, ao atingir a temperatura de degradação, que é de $200{ }^{\circ} \mathrm{C}$, e até a temperatura máxima de ensaio, que é de $300{ }^{\circ} \mathrm{C}$, o tempo decorrido é de apenas $10 \mathrm{~min}$. O segundo fator é que, quando do envelhecimento dos fluidos no equipamento Roller Oven, embora a temperatura máxima de ensaio $\left(177^{\circ} \mathrm{C}\right)$ seja atingida em um período de $3 \mathrm{~h}$, os fluidos permanecem nessa temperatura por um intervalo de $16 \mathrm{~h}$, o que parece ser decisivo para a degradação parcial ou total dos componentes do fluido e do próprio fluido de perfuração. Como complemento a esse fator, os aditivos encontram-se na forma hidratada, o que favorece o processo de degradação em temperaturas mais baixas.

A perfuração de um poço de petróleo é uma operação bastante complexa e sempre estará sujeita à ocorrência de uma série de anormalidades. Essas complicações são altamente indesejáveis e causam muitos prejuízos. Assim, é essencial conhecer a composição e otimizar as propriedades dos fluidos de perfuração, pois o principal desafio na formulação dos fluidos é atender às condições cada vez mais severas (altas temperaturas e pressões) em poços profundos e às exigências ambientais. 


\section{CONCLUSÕES}

Com o objetivo de avaliar a estabilidade térmica de fluidos de perfuração argilosos aditivados com polímeros e lubrificante sob elevadas temperaturas, concluiu-se que: (i) a temperatura tem grande influência sobre as propriedades dos fluidos, promovendo a redução dos valores de viscosidades aparente e plástica e o aumento do volume de filtrado; (ii) o envelhecimento térmico a temperaturas acima de $100{ }^{\circ} \mathrm{C}$ provoca a degradação dos fluidos, sendo esta comprovada pelo escurecimento da sua coloração, pelo processo de caramelização e pela redução do $\mathrm{pH}$; e (iii) os fluidos estudados têm sua estabilidade térmica comprometida, uma vez que a temperatura favorece a hidrólise, promovendo ruptura da cadeia principal dos polímeros e, no caso do lubrificante, formação do ácido carboxílico e álcool. Além disso, por estarem na forma hidratada, os polímeros e lubrificante estão mais suscetíveis à degradação.

\section{AGRADECIMENTOS}

À CAPES, pelo apoio financeiro, e ao CNPq (Processo no 305729/2010-1), pelo apoio financeiro da bolsa de produtividade; à Empresa Bentonit União Nordeste Ltda. - BUN, pelo fornecimento da argila bentonítica; à Empresa System Mud Indústria e Comércio Ltda., pelo fornecimento dos aditivos e apoio a este projeto; e ao PeFLab e ao LABDES, pelo uso de suas instalações físicas.

\section{BIBLIOGRAFIA}

[1] NERY, G.G., MACARI, R. "Os fluidos de perfuração usados na indústria da água subterrânea e a sua influência sobre os perfis geofísicos de princípio elétrico", Águas Subterrâneas, v. 19, n.1, pp. 49-60, 2005.

[2] GUIMARÃES, I.B., ROSSI, L.F.S, "Estudo dos constituintes dos fluidos de perfuração: proposta de uma formação otimizada e ambientalmente correta", In: $4^{\circ}$ Congresso Brasileiro de Petróleo e Gás - PDPETRO. Campinas, São Paulo, 2007.

[3] LUMMUS, J.L., AZAR, J.J, Drilling fluids optimization a practical field approach, Penn Well Publishing Company, Tulsa, Oklahoma, 1986.

[4] FELIX, T.F., ARRUDA, J.T., MEDEIROS, A.C.R., et al., "Fluidos de perfuração à base de água: avaliação da lubricidade e controle de inchamento de argilas", In: III Encontro Nacional de Hidráulica de Poços, Campos do Jordão, São Paulo, 2009.

[5] THOMAS, J.E. Fundamentos de engenharia de petróleo, Editora Interciência, Rio de Janeiro, 2001.

[6] DARLEY, H.C.H., GRAY, G.R., Composition and properties of drilling and completion fluids, Fifth Edition, Gulf Publishing Company, Houston, Texas, 1988.

[7] BORGES, C.D., VENDRUSCOLO, C.T., SEMINA, Ciências biológicas e da saúde, v. 29, n. 2, pp. 171-188, 2008.

[8] LUVIELMO, M.M., SCAMPARINI, A.R.P., "Goma xantana: produção, recuperação, propriedades e aplicação", Estudos tecnológicos, ISSN 1808-7310, vol. 5, nº 1, pp. 50-67, 2009.

[9] NAVARRETE, R.C., SEHEULT, J.M., COFFEY, M.D., "New biopolymer for drilling, drill-in, completions, spacer, and coil-tubing fluid, part II", In: International Symposiumon Oil field Chemistry, SPE 64982, p. 1-1, 2001.

[10] BORGES, C.D., VENDRUSCOLO, C.T., MARTINS, A.L., et al., "Comportamento reológico de xantana produzida por Xanthomonas arborícola pv pruni para aplicação em fluido de perfuração de poços de petróleo", Polímeros: Ciência e Tecnologia, vol. 19, nº 2, pp. 160-165, 2009.

[11] ROCKS, J.K., "Xanthan gum” Food Technology, Chicago, v. 25, n. 5, pp. 476-483, 1971.

[12] CUVELIER, G., LAUNAY, B., "Concentration regimes in xanthan gum solutions deduced from flow and viscoelastic properties", Carbohydrate Polymers, Barking, v. 6, n. 5, pp. 321-333, 1986.

[13] PEREIRA, E.,Química dos polímeros e aplicações - parte IV, disponível em: www.systemmud.com.br, acesso em: dezembro, 2006.

[14] PEREIRA, E., "Uso de inibidores de argilas como solução de problemas em sondagens", http://www.systemmud.com.br/index.php?PG=literatura\&sub=literatura_home\&artigo=lit_006, Acessado em 20 de abril de 2010.

[15] GOMES, H.O., FILHO, J.F.O., "Metodologia de avaliação da lubricidade de óleo diesel”, In: Encontro para a Qualidade de Laboratórios, São Paulo, junho, 2005. 
[16] BUSHNELL-WATSON, Y.M., PANESAR, S.S., "Mechanisms of differential sticking and a simple well site test for monitoring and optimizing drilling mud properties", In: SPE 22549, 1991.

[17] REID, P.I., MEETEN, G.H., WAY, P.W., "Mechanisms of differential sticking and a simple well site test for monitoring and optimizing drilling mud properties", In: IADC/SPE 35100, Drilling Conference New Orleans, Louisiana, 12-15 March, 1996.

[18] CLARK, R.K., "Impact of environmental regulations on drilling fluid technology", Journal Petroleum Technology, v.46, n9, pp. $804-809,1994$.

[19] KELLY, J. Jr., Hwk, D.E., "Mud additives in deep wells", Oil Gas Journal, Oct.,1961.

[20] KNECHTEL, M.M., PATTERSON, S.H., "Bentonite deposits in marine cretaceous formations, Hardin District, Montana and Wyoming", U.S. Geol. Survey Bull 1023. Drilling Fluids Components 605.(1956)

[21] API, Petroleum and natural gas industries - Field testing of drilling fluids - Part 1: Water-based fluids, ISO/WD 10414-1 e ISO TC 67/SC 3 N, 2005.

[22] FARIAS, K.V., Influência de umectante aniônico na reologia e espessura de reboco de fluidos hidroargilosos, Tese M. Sc., Engenharia Química, Centro de Ciências e Tecnologia, Universidade Federal de Campina Grande - UFCG, Campina Grande. Paraíba, 2005.

[23] API, Norma API Recommended Practice 13B-1, 2003.

[24] VILLETTI, M.A., CRESPO, J.S., SOLDI, M.S., et al., "Thermal degradation of natural polymers", Journal of thermal analysis and calorimetry, v. 67, pp. 295-303, 2002.

[25] SOARES, R.M.D., LIMA, A.M.F., OLIVEIRA, R.V.B., et al., "Thermal degradation of biodegradable edible films based on xanthan and starches from different sources", Polymer degradation and stability, v.90, pp. 449-454, 2005.

[26] FRANCO, A.P., Caracterização estrutural e adsorção de íons metálicos por carboximetilcelulose e quitozana in natura e empregada com zeólita, Tese Pós-Graduação em Química, Universidade Federal do Paraná, Curitiba, janeiro de 2009.

[27] MAGALHÃES, J. Contatos pessoais, 2012.

[28] MORIYAMA, A.L.L., NETO, E.L.B., Avaliação da influência do envelhecimento nas propriedades de fluidos de perfuração base água, Plano de trabalho de pesquisa,

http:www.nupeg.ufrn.br/.../PRH14for17_andre_moriyama_gra_nov_2008.doc. Acessado em setembro de 2011.

[29] FÉLIX, T.F., VIDAL, E.L.F., GARCIA, R.B., et al., "Desenvolvimento de fluidos de perfuração à base de água com alta capacidade de inibição e alta lubricidade", In: $4^{\circ}$ PDPETRO, Campinas, SP, 2007.

[30] MATOS, P.R.R., Utilização de óleos vegetais como base de óleos lubrificantes, Tese de M.Sc., Instituto de Química, Universidade de Brasília, Brasília, DF, Brasil, 2011.

[31] VENTURINI, C.L., Substâncias Anfifílicas: Parte A, http://www.ebah.com.br/content/ABAAAfAWYAL/sistemas-dispersos?part=4\# Acessado em maio de 2013.

[32] LOMBA, R. Fundamentos de filtração e controle de filtrado de fluidos de perfuração. Apostila. 2010.

[33] FENNEMA, O.R. Química de los alimentos, 2 ed. Zaragoza, Acribia S.A , 2000.

[34] COULTATE, T.P. Alimentos: a química de seus componentes, 3 ed., Artmed, Porto Alegre, 2004.

[35] ARAÚJO, J.M.A.Química de alimentos. 2 ed., UFV, Viçosa, 1995.

[36] ARAÚJO, L.M., SANTOS, N.F., ARAÚJO, N.C.M., et al., "Influência da temperatura e do pH no processo de caramelização da sacarose", In: X Jornada de ensino, pesquisa e extensão - JEPEX 2010 UFRPE, Recife, 2010. 